\title{
Stoping sequence optimisation at Eleonore Mine based on stress analysis through horizon scale numerical modelling
}

\author{
L. Bouzeran' ${ }^{1}$, M. Pierce ${ }^{2}$, A. Jalbout ${ }^{3}$, and M. Ruest ${ }^{3}$ \\ 1'Itasca Consulting Group Inc, USA \\ 2Pierce Engineering, USA \\ ${ }^{3}$ Goldcorp Inc, Canada
}

\begin{abstract}
The orebody at Eleonore Mine (Eleonore) consists of multiple lenses of narrow thickness. Owing to ground stability issues, the capacity of the support was increased and the mine sequence was changed successfully in 2016. In 2018, mine-scale geomechanical numerical analyses were conducted in the continuum code FLAC3D to better understand the conditions leading to these improvements and further optimise the sequence. Locations of falls of ground and damage, blast hole performance and a micro-seismic database were used to calibrate the model, and different future mining sequences were analysed. The models helped demonstrate that persistent shallow dipping joints subject to high horizontal stress put a lot of demand on bolts in the back of excavation; they are likely to be the main source of energy release as they are sheared peripheral to the top and bottom of the stopes. The narrow-mined width and good rock strength involve limited stope interaction, resulting in highly stressed remnant stopes and limited impact of the sequence.
\end{abstract}

\section{INTRODUCTION}

In 2016, due to ground stability issues, the mine, located in the James Bay area of Northern Quebec, had to increase the capacity and type of support and change the mining sequence in order to manage some of the risks related to ground conditions. These changes were successful in reducing instability issues, but the underlying mechanisms were not fully understood. Changing the mining sequence resulted in less flexibility, affecting future ramp-up in mine production. Geomechanical analyses of stoping sequence options at Eleonore were conducted with the continuum code FLAC3D (Itasca, 2017) as the mine is currently in the process of re-evaluating the strategy chosen to mine the ore body. The goal was to explore other mining options and compare them based on specific criteria.

\section{SITE DESCRIPTION}

Eleonore is divided into 6 horizons, with horizon 1 being the closest to surface (first level $80 \mathrm{~m} \mathrm{deep}$ ) and horizon 6 currently being the deepest planned horizon (down to about $1300 \mathrm{~m}$ deep). The stope height and level spacing at Eleonore is typically $30 \mathrm{~m}$. The site exhibits the following characteristics: (1) the orebody consists of multiple lenses of narrow thickness and variable grade (stope delineation at the time of the project is shown in Figure 1); (2) the rock is relatively homogenous and the dominant Greywacke unit is strong and brittle with a UCS of about 160MPa; (3) persistent sub-horizontal joints at close spacing ( 30 to $50 \mathrm{~cm}$ ) dominate in upper horizons 1 to 4 , with some other vertical crossing joints present (leading to a GSI close to 60); and (4) Pegmatite can be present locally and is pretty competent but contacts can be weak. There is also evidence of high horizontal stress with a locked-in component at surface. Access to the mine is through the hanging wall due to the presence of water above the footwall and mining fronts often converge toward large intersections as shown in Figure 1. 

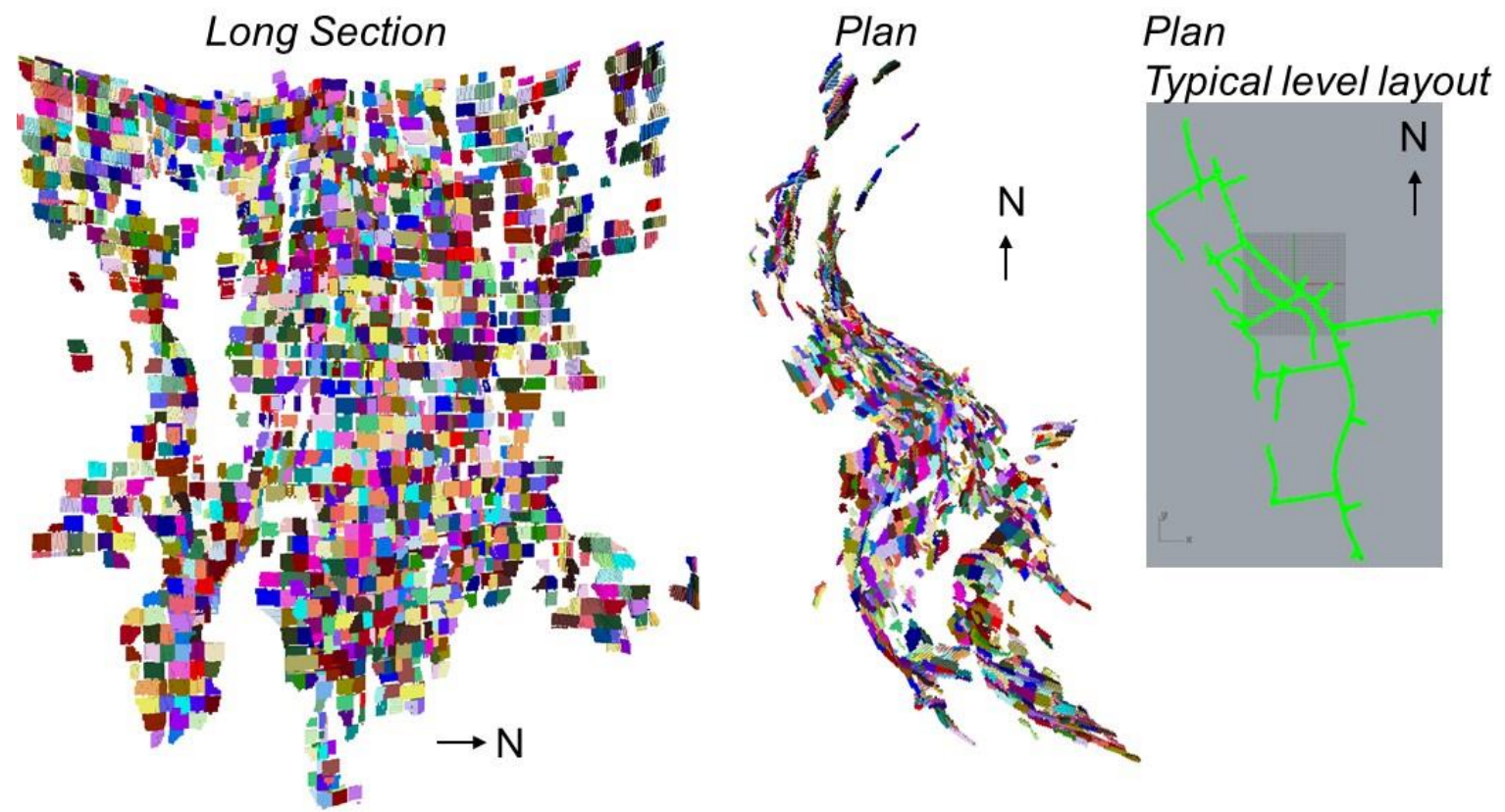

Figure 1 - Left: Eleonore mine's orebody (each stope is assigned a different colour) Right: Eleonore's typical layout - plan view of level 200 in horizon 1 (north to the left)

These geotechnical and operational characteristics have several impacts on performance. Persistent shallow dipping joints subject to high horizontal stress put a lot of demand on bolts in the back of excavation: bolts can be intensely sheared locally, and adequate ground support implementation can be challenging. The narrow-mined width means that stopes do not interact much along strike or not enough to yield secondaries (i.e., remnant stopes) that remain highly confined. Thus, when mining is significantly advanced, secondary stopes, where large intersections are often present, can become highly stressed, especially if they exhibit a small strike length, as shown in Figure 2. However, the limited amount of yielding has the advantage of offering flexibility to sequencing. Finally, the narrow thickness of the orebody (i.e., a few metres) means that the controlling span is reached very quickly, after one or two stopes are taken along strike. This aspect also gives flexibility to the sequence, allowing, for example, consideration of a flat back type sequence.

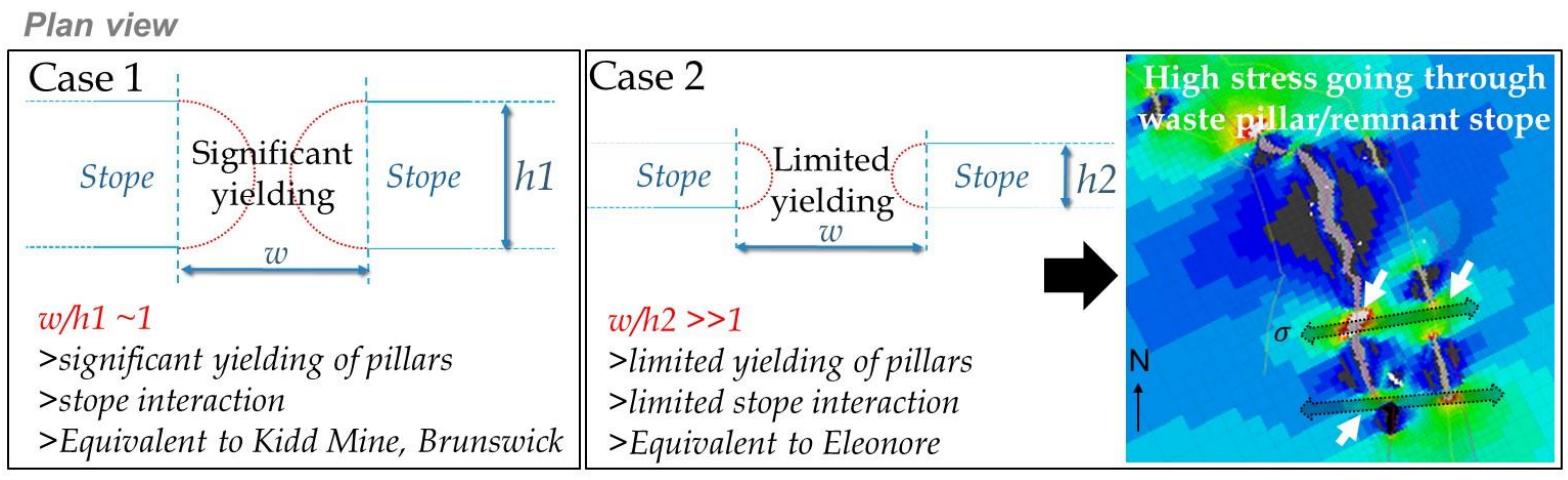

Figure 2 - Left: Impact of mined width on secondary/pillar performance Right: Plan view showing waste pillars attracting high stress 


\section{MODEL DESCRIPTION}

\section{Geometry, geology and mining sequence}

The models and results presented in this paper focus on the evaluation of horizons 1 to 4 . Horizon-scale FLAC3D simulations were performed to study the impact of the mining sequence on the level of stress recorded near open excavations. Indeed, the geomechanical risk is mainly related to stress, local conditions, and time, but the main factor affected by the sequence is usually stress. FLAC $3 D$ is a continuum code that has the ability to model the plastic behaviour of the rock mass upon excavation of a large volume of rock (i.e., a whole mine or portion of a mine) in a reasonable amount of time. Computation time increases exponentially with the size of the model; hence, the horizons are studied two by two to allow each simulation to be run in a manageable amount of time (i.e., one model focuses on horizons 1 and 2 and one on horizons 3 and 4). Each model includes a coarse representation of the horizon above the two analysed, when relevant. Two sequence options are studied and compared for horizons 1 and 2. The base case option (referred as Option 1) is a sequence built with limited geomechanical restrictions. The second option (referred to as Option 2) corresponds to a flat back sequence. Because mining of horizons 3 and 4 is already quite advanced, there is less flexibility for a change of sequence at this point; hence, only the current planned sequence for these two horizons is studied and referred to as Option 1 (i.e., base case).

In each model, each stope is represented and mined out based on the schedule corresponding to the given sequence option. A time increment of 15 days is used, which means that all the stopes mined in a 15-day window are excavated at the same time before the model is cycled to reach equilibrium and the next phase is started. All the phases are modelled similarly (between 100 and 150 phases for one simulation) until the end of the sequence is reached. Stopes are backfilled based on the backfill dates recorded by the mine (for past mining), or after a 16-day period by default for future stopes, with a fixed strength material. Only on-ore accesses are represented in the model. Each stope's undercut is excavated as the stope itself is being excavated. The horizon-scale model does not consider the excavation of the accesses; only the stopes get excavated in the model. Also, because the Greywacke is highly dominant at Eleonore and showed consistent strength around the orebody during mapping (Oke and Kalenchuk, 2017), and other units are poorly constrained in space, the model does not consider local variation in the rock mass condition. Other units encountered on site, such as Pegmatite, are not modelled. We believe this is reasonable for the large-scale sequencing comparison exercise of this project. The model can indicate hot spots where stress will be elevated and likely induce challenges for drift stability, but the model is not capable of predicting further increases of stress due to access excavation (especially in high extraction areas where several intersections are present) nor can it predict local stress variation and induced instability due to the presence of weaker Greywacke conditions, different local units such as pegmatite dikes, or heavy jointing. No fault with large-scale slip potential was identified on site so far and, hence, no major structures are considered in the model.

\section{Constitutive model and properties}

All models use the CaveHoek constitutive model (Pierce, 2013) to simulate the rock mass behaviour. The CaveHoek constitutive model can simulate the strain-softening behaviour and uses the HoekBrown envelope for the peak and residual strength. It also allows for representation of modulus softening, density adjustment, dilation, dilation shutoff, scaling of properties to zone size, cohesion weakening, tension weakening and frictional strengthening. The presence of very persistent subhorizontal joints in horizons 1 to 4 at tight spacing (about $0.5 \mathrm{~m}$ - Oke and Kalenchuk, 2017) is believed to play a key role at a large scale in terms of yielding of the rock mass and associated stress redistribution, as well as for the seismicity. Therefore, they are represented in the horizon-scale models with the ubiquitous joint model (Clark, 2006); this formulation is an option in the FLAC3D CaveHoek constitutive model that accounts for the presence of closely spaced planes of weakness. The criterion for failure on the plane, whose orientation is given, consists of a composite Mohr-Coulomb envelope with tension cut-off. Rock mass and ubiquitous joint properties used for the horizon-scale models were based on small-scale back analysis of a collapsed intersection and are listed in Table I. 
Table I. Properties of the Greywacke (Continuum) and persistent sub-horizontal joints (Ubiquitous joints)

\begin{tabular}{|l|l|l|l|l|l|l|l|l|l|}
\hline \multicolumn{2}{|l|}{ Continuum (Hoek-Brown parameters) } \\
\hline GSI & $\sigma_{\mathrm{ci}}(\mathrm{MPa})$ & $\mathrm{mi}$ & $\mathrm{E}_{\mathrm{i}}(\mathrm{GPa})$ & Density & $\mathrm{E}_{\mathrm{rm}}(\mathrm{GPa})$ & $\mathrm{v}$ & $\mathrm{m}_{\mathrm{rm}}$ & $\mathrm{s}$ & $\mathrm{a}$ \\
\hline 63 & 162 & 11 & 39 & 2750.0 & 23 & 0.226 & 2.934 & 0.0164 & 0.502 \\
\hline Ubiquitous joints (Mohr-Coulomb parameters) \\
\hline $\begin{array}{l}\text { Tension } \\
(\mathrm{Pa})\end{array}$ & $\begin{array}{l}\text { Cohesion } \\
(\mathrm{Pa})\end{array}$ & $\begin{array}{l}\text { Friction } \\
\left({ }^{\circ}\right)\end{array}$ & $\begin{array}{l}\text { Residual } \\
\text { friction }\left({ }^{\circ}\right)\end{array}$ & $\begin{array}{l}\text { Dilation } \\
\left({ }^{\circ}\right)\end{array}$ & Brittleness \\
\hline $5 \mathrm{e} 5$ & $2.5 \mathrm{e} 6$ & 40 & 40 & 10 & Perfectly brittle \\
\hline
\end{tabular}

\section{In-situ stress}

Based on the two available stress measurements (Yong 2014, Corthésy and Leite 2017), it was assumed that the major principal stress is sub-horizontal and oriented 64 degrees from north, and that the other two principal stress are vertical and sub-horizontal. It has also been assumed for the modelling exercise that $\sigma_{2}=\sigma_{3}$. Based on the observations and small-scale case studies of some of the falls of grounds in horizon 1 and 2 of significant seismicity and instabilities, it has been decided to assume that a locked-in stress exists at surface, which is typical of regions that have experienced post-glacial rebound such as the northern part of Canada. For this reason, a locked-in stress of $19 \mathrm{MPa}$ has been assumed at surface for $\sigma_{1}$. The same uniform gradient is assumed for all the stress components. This corresponds to a $\mathrm{K}$ ratio $\sigma_{\mathrm{H}} / \sigma_{\mathrm{V}}$ of about 5 at 200 metres depth and about 3 at 400 metres depth, which is realistic based on the literature (Hoek and Brown, 1980).

\section{MODELING RESULTS}

\section{Stope stress and score evaluation}

Since each model encompasses hundreds of stopes, an automatic stress evaluation of each stope is performed. The following quantities/stability aspects are queried for each stope: (1) the mean stress in the stope prior to excavation, which relates to the overall stability of the stope (drift stability, drilling performance); (2) the mean and max stress in the undercut region (i.e., stress expected in the back of the undercut drift prior to excavation of the stope), which relates to the stability of the undercut prior to excavation of the stope; and (3) the maximum stress peripheral to the stope prior to and after excavation, which relates to the presence of a waste pillar (or simply highly stressed ground) very close to the stope prior to or after excavation and can increase the risk of stope and drift instability in the area. Error! Reference source not found. 3 illustrates the automatic stope stress evaluation performed for each stope. Each stope is then attributed a "total score" that is a combination of the three quantities described above and, hence, reflects the overall level of stress expected in the stope. The scoring is done such that a high level of stress increases the score and, hence, the geomechanical risk, as presented in Figure 3. Thus, a low score is desired.

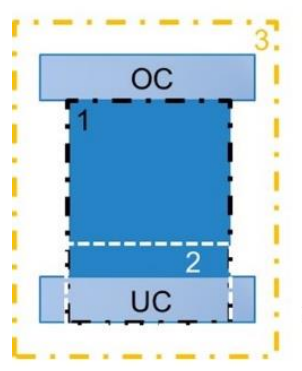

$\begin{array}{cc}\text { Low Stress } & \text { Moderate Stress Conditions } \\ \text { Conditions } & \text { MODERATE SCORE }=10-16, \\ \text { LOW Score }<10, & \text { S1 60-80 MPa } \\ \text { S1<40-60 MPa } & \text { Hole cleaning } \\ \text { - Favorable for } & \bullet \text { Spalling in the backs } \\ \text { mining } & \text { - More careful support } \\ \text { - Standard support } & \text { required }\end{array}$

Figure 3. Left: Automatic stope stress evaluation performed for each stope: (1) stope average; (2) in the undercut 
area only; and (3) near the stope. Right: Score evaluation for each stope and associated potential risks

The weight of each of these three stress quantities (the mean stress in the stope prior to excavation, the mean and max stress in the undercut region, and the maximum stress near the stope prior and after excavation) in the calculation of the total score has been adjusted to optimize the correlation between the total score and the data available for past mining (i.e., locations of high blast hole cleaning percentage and falls of ground). The best correlation was achieved when applying a similar weight to each quantity. By applying this stress evaluation and scoring to each stope, statistics can then be gathered at the horizon scale for past mining and applied to future mining to compare different sequences. It is important to note that the scoring and risk rating is solely based on the level of stress recorded in the stope. On site, problems arise from stress conditions but also local ground conditions, the local extraction ratio, the quality of the support installation, and time. Hence, a low score does not guarantee an absence of problems (but the risk is lower), and a high score does not guarantee the problems listed above (but the risk is higher).

\section{Model calibration}

The mine provided four sets of data that were used to compare model results and ground behavior observed on site to make sure the modeling approach is relevant: (1) the location of falls of ground; (2) the cleaning and redrilling percentage (meters cleaned/meters drilled) for blast holes in each stope mined to date; (3) the seismic database; and (4) the historical evidence of access damage.

\section{Falls of ground}

The model has been examined at the same locations and times of these falls to understand the key factors and the role of stress and geomechanics in general in these events. It appeared that in most cases, the falls were related primarily to: (1) a ground support problem (i.e., either the design itself or the implementation of the design); and (2) a stress problem due to the local geometry of the excavation (large opening and/or waste pillars concentrating stress in the vicinity). Hence, these two root causes are not related to the global sequence and are likely manageable with adequate timing and design of the support installation. These observations made at an early stage of the project have eliminated some key reasons to change the sequence and put more focus on analysing local conditions and optimizing the ground support to manage the geomechanical risk at Eleonore. It also suggested that there was potential to make the sequence more flexible without significantly increasing the geomechanical risk. This was supported by the results of horizon-scale modelling presented in this paper.

\section{Blast hole cleaning}

The mine has provided percentages of cleaning and redrilling for blast holes in each stope mined in the past. This data has been carefully analysed to see if the highly stressed stopes identified in the model were also highlighted by high percentages of cleaning or redrilling in the data (See Figure 6).

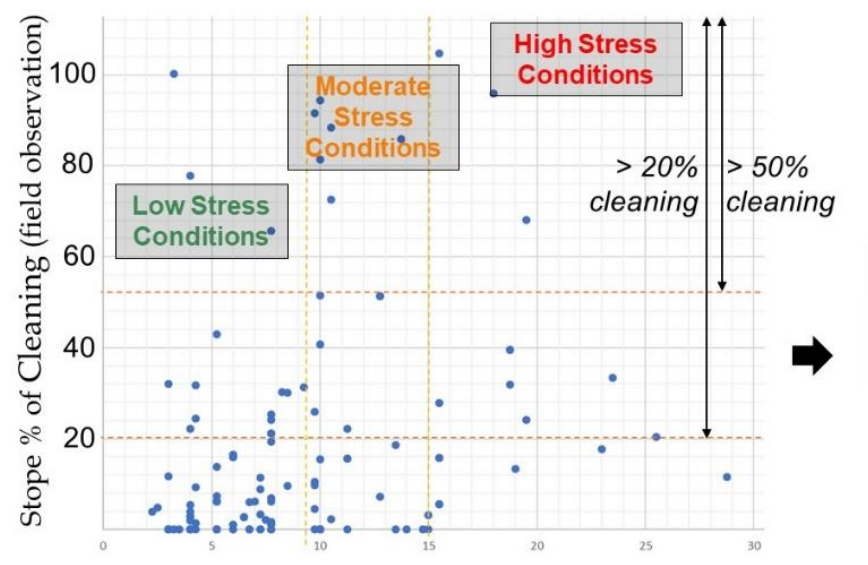

Expected \% of stopes to exhibit $20 \%$

or $50 \%$ cleaning based on score:

\begin{tabular}{|l|l|l|l|}
\hline & $\begin{array}{c}\text { If LOW } \\
\text { score }\end{array}$ & $\begin{array}{c}\text { If MOD. } \\
\text { score }\end{array}$ & $\begin{array}{c}\text { If HIGH } \\
\text { score }\end{array}$ \\
\hline $\begin{array}{l}\text { Cleaning }>20 \% \\
\text { (\% of stopes) }\end{array}$ & $19 \%$ & $35 \%$ & $59 \%$ \\
\hline $\begin{array}{l}\text { Cleaning }>50 \% \\
\text { (\% of stopes) }\end{array}$ & $4 \%$ & \multicolumn{2}{|c|}{$24 \%$} \\
\hline
\end{tabular}

Figure 6. Left: Cleaning percentage versus total score for each stope mined in horizons 1 and 2 in the past. 
Right: Statistics on cleaning percentage in Horizons 1 and 2 based on stope total score

Different comparisons between the model results and the data have been made: blast hole redrilling and cleaning data were compared to each of the stope stress evaluation criteria (i.e., the mean stress in the stope prior to excavation, the mean and max stress in the undercut region, and the maximum stress in the vicinity of the stope prior to and after excavation), as well as the total score (which is a combination of these three quantities). Although no correlation could be established between redrilling and measured stress, a certain pattern could be established when comparing the cleaning percentage and the total score of each stope, as shown in Figure 6: the correlation between a stope cleaning percentage and its score is not direct, but one can identify score thresholds beyond which the risk of a high cleaning percentage increases. For example, below a score of 10, most stopes have experienced negligible or less than $30 \%$ of cleaning, while above 10, most stopes have experienced between 10 and $100 \%$ cleaning. Based on feedback from the mine, it appears that redrilling often can be due to operational issues (e.g., hole deviation), while cleaning is more likely to be due to ground conditions, but not always. This can explain that the level of stress correlates better with the cleaning than redrilling percentage. Several thresholds have been tested to define the most relevant values of a stope score to predict

stress-related

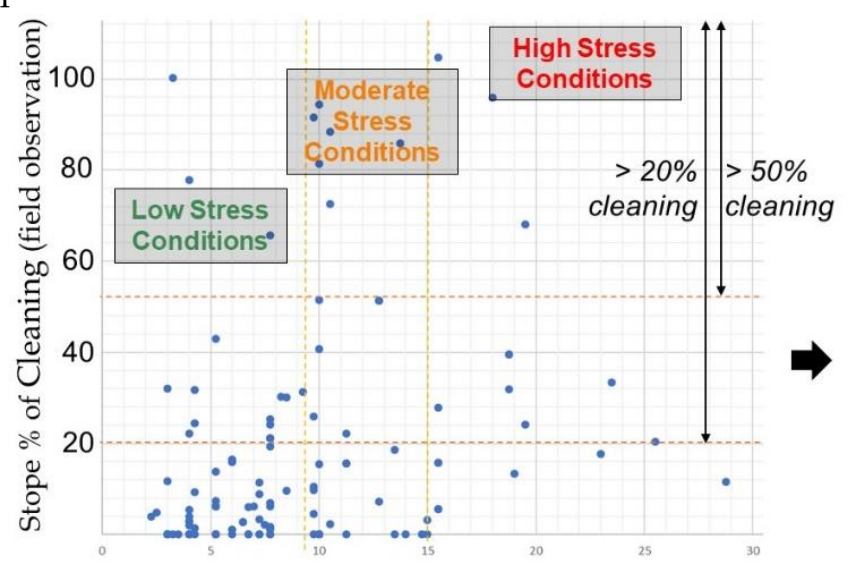

drilling

problems.

Figure shows the data and thresholds established for horizons 1 and 2 as well as the corresponding statistics. Comparison for past mining between the model and available data shows that $19 \%$ of the stopes with a low score (i.e., $<10$ ) have experienced above $20 \%$ of cleaning, while $35 \%$ of the stopes with a moderate score (i.e., 10 to 16 ) have experienced more than $20 \%$ of cleaning and $59 \%$ of the stopes with a high score (i.e., > 16) have experienced more than $20 \%$ of cleaning. It also appears that $4 \%$ of the stopes with a low score have experienced more than $50 \%$ of cleaning while $24 \%$ (i.e., 5 times more) of the stopes with a moderate to high score have experienced more than $50 \%$ of cleaning. These numbers can be applied to future mining in horizons 1 and 2 to predict blast hole cleaning requirements based on stope scores for each sequence and compare them.

\section{Seismic moment evaluation}

The persistent sub-horizontal joints present in horizons 1 to 4 at Eleonore are likely to be sheared at the top and bottom of the stopes (where stress is wrapping around the mined area) and induce seismicity due to joint slip, as shown in Figure 7. 


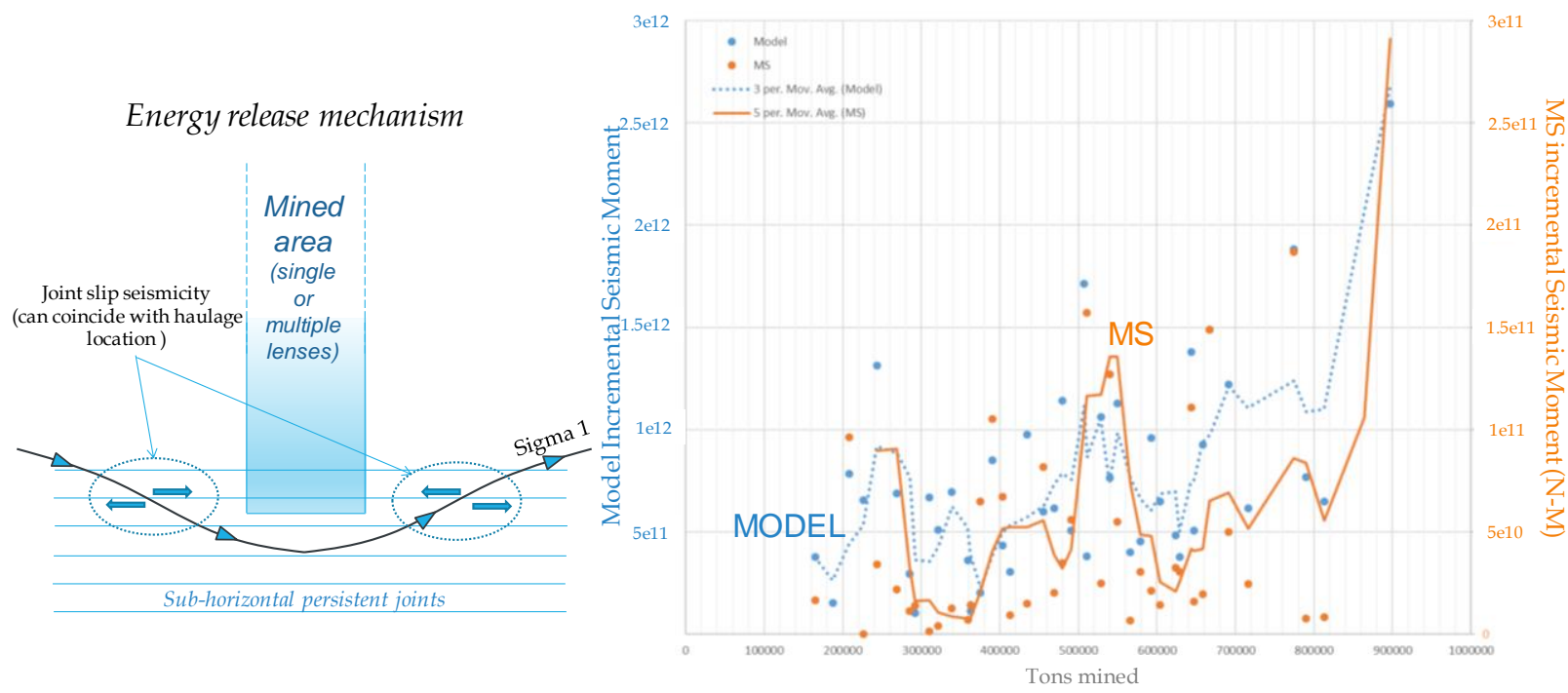

Figure 7. Left: Rotation of sigma 1 and potential for joint slip on sub-horizontal joints at top and bottom of stoping area. Right: Incremental seismic moment for two- to four-week periods generated in horizons 1 and 2 in the past as acquired by the monitoring system and in the model

Based on the assumption that slip on horizontal joints is the main source of energy release in horizons 1 to 4 , seismic moments were used to compare the seismic response between the model and reality. The mine provided the seismic database, such that the seismic moment for each event in the database is known; and the seismic moment can be binned and summed for events in the same two-week time period employed for model solution. Seismic moment can be calculated from a slip model for seismicity based on the slip area (A), the average slip magnitude (ASM) and the shear modulus (G):

$$
\text { Seismic moment }=\mathrm{A} \times \mathrm{ASM} \times \mathrm{G}
$$

In the model, each zone has a slip potential related to shear on the horizontal ubiquitous joints; hence, the seismic moment for a given zone is quantified from the zone's shear modulus and the following definition of ASM and A, based on the zone's joint plastic shear strain $\left(\xi_{j p}\right)$ and the zone length $(\mathrm{L})$ :

$$
\begin{aligned}
& A S M=\xi_{\text {jp }} \times L \\
& A=L^{2}
\end{aligned}
$$

This way, the seismic moment can be assessed in the model and compared on a two-week basis with the seismic data. Even though this approach to seismic moment evaluation has limitations (i.e., it does not consider the impact of $\mathrm{H} 3$ in the $\mathrm{H} 1-\mathrm{H} 2$ model or the impact of accesses and, hence, the asymmetry between hangingwall and footwall), it has proved to be successful in estimating seismic activity variation on horizons 1 and 2 (as shown in Figure 7), and horizons 3 and 4 . Figure 7 shows the incremental seismic moment generated in horizons 1 and 2 in the past as acquired by the monitoring system and in the model for equal time periods of two to four weeks. It can be seen that: (1) modelled incremental seismic moment from horizontal joint slip in the model is in reasonable agreement with the incremental moment calculated from the MS database, which supports horizontal joint slip as a source mechanism of seismicity; and (2) there is about one order of magnitude difference between the modelled seismic moment and reality. The model picks up HW and FW deformation and translates all the deformation into seismic moment (no sensitivity threshold as for a seismic acquisition system and 100\% seismic efficiency); which can explain (at least partially) the one order of magnitude difference when compared to the MS data. In addition to this, a spatial micro-seismicity cluster analysis of the seismic data performed by the mine (Guido, 2018) also supports horizontal joint slip as a source mechanism of seismicity. 


\section{Conclusion}

The mine provided four sets of data that were used to compare model results and reality and allowed us to build confidence in the representativeness of the model and its ability to be used for forward analyses. Three critical observations were made. First, the total stress score for the stope (considering stress in the stope and surrounding the stope) is the best predictor for significant blast hole cleaning. Even though stopes with a large percentage of blast hole cleaning correlate with high stress areas in the model, the correlation is not direct. This means it is possible that a low-scored stope can be very problematic and a highly scored stope can be mined without any problem, although it's less likely to happen than the opposite. Finally, the modelled incremental seismic moment from horizontal joint slip in the model over two- to four-week periods is in reasonable agreement with the cumulative moment calculated from the MS database, which supports horizontal joint slip as a source mechanism of seismicity.

\section{Base case sequence}

Stress level

The stress evaluation performed on the stopes allows calculation of key stress values for each horizon. Table IV summarizes these values for the base case mining sequence. We can see that stress conditions get significantly more challenging in horizons 3 and 4 compared to horizons 1 and 2: (1) the mean back stress in horizons 1 and 2 is between 0 and 60MPa and between 20 and $80 \mathrm{~Pa}$ in horizons 3 and 4; (2) 10 to $20 \%$ of the accesses experience a stress above $80 \mathrm{MPa}$ locally in horizons 1 and 2, while $15 \%$ to $25 \%$ of the accesses experience a stress over 120MPa locally in horizons 3 and 4; and (3) high stress stopes (experiencing stress $>80-100 \mathrm{MPa}$ locally) represent about $10 \%$ of the stopes in horizons 1 and 2 , and about $40 \%$ of the stopes in horizons 3 and 4 .

Table IV. Key values per horizon for base case sequence

\begin{tabular}{|c|c|c|c|c|c|c|c|c|c|c|}
\hline 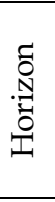 & 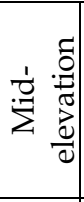 & $\begin{array}{l}\text { In-situ } \\
\text { sigma } \\
1 \text { mag. }\end{array}$ & $\begin{array}{l}\text { In-situ } \\
\text { sigma } \\
3 \text { mag. }\end{array}$ & $\begin{array}{l}\text { In- } \\
\text { situ } \\
\text { stress } \\
\text { ratio }\end{array}$ & $\begin{array}{c}\% \\
\text { stope } \\
\text { at } \\
\text { high } \\
\text { score } \\
\end{array}$ & $\begin{array}{l}\text { Mean } \\
\text { back } \\
\text { stress } \\
(\mathrm{MPa})\end{array}$ & $\begin{array}{l}\text { Local max } \\
\text { back stress }\end{array}$ & $\begin{array}{c}\text { Stopes at } \\
\text { very } \\
\text { high } \\
\text { score } \\
(>32) \\
\end{array}$ & $\begin{array}{c}\text { Stopes } \\
>20 \% \\
\text { blast } \\
\text { hole } \\
\text { cleaning }\end{array}$ & $\begin{array}{c}\text { Stopes } \\
>50 \% \\
\text { blast } \\
\text { hole } \\
\text { cleaning }\end{array}$ \\
\hline 1 & 140 & 23 & 4 & 6.0 & $7 \%$ & $0-60$ & $12 \%>80 \mathrm{MPa}$ & \multirow{2}{*}{0} & $24 \%$ & $7 \%$ \\
\hline 2 & 335 & 28 & 9 & 3.1 & $11 \%$ & $20-60$ & $22 \%>80 \mathrm{MPa}$ & & $27 \%$ & $10 \%$ \\
\hline 3 & 545 & 34 & 15 & 2.3 & $42 \%$ & $20-80$ & $\begin{array}{c}22 \%>120 \\
\mathrm{MPa}\end{array}$ & \multirow{2}{*}{$\begin{array}{c}54 \\
(/ 476)\end{array}$} & $55 \%$ & $31 \%$ \\
\hline 4 & 725 & 39 & 20 & 2.0 & $40 \%$ & $20-80$ & $\begin{array}{c}22 \%>120 \\
\mathrm{MPa}\end{array}$ & & $56 \%$ & $31 \%$ \\
\hline
\end{tabular}

\section{Stress increase factors}

The model was used to better understand the factors that can increase the stress in and surrounding a stope by analysing longitudinal views of the main lenses (As shown in Figure 8) through the mining sequence. Stress can be elevated in a stope or near a stope due to the combination of several stress increase factors. Table $\mathrm{V}$ lists these factors and possible remediation. Figure 8 gives examples of locations where each factor is affecting stress in horizons 3 and 4 on lens 5050, one of the most continuous lenses throughout the mine as well as the lens identified as the most challenging in terms of stress conditions. 


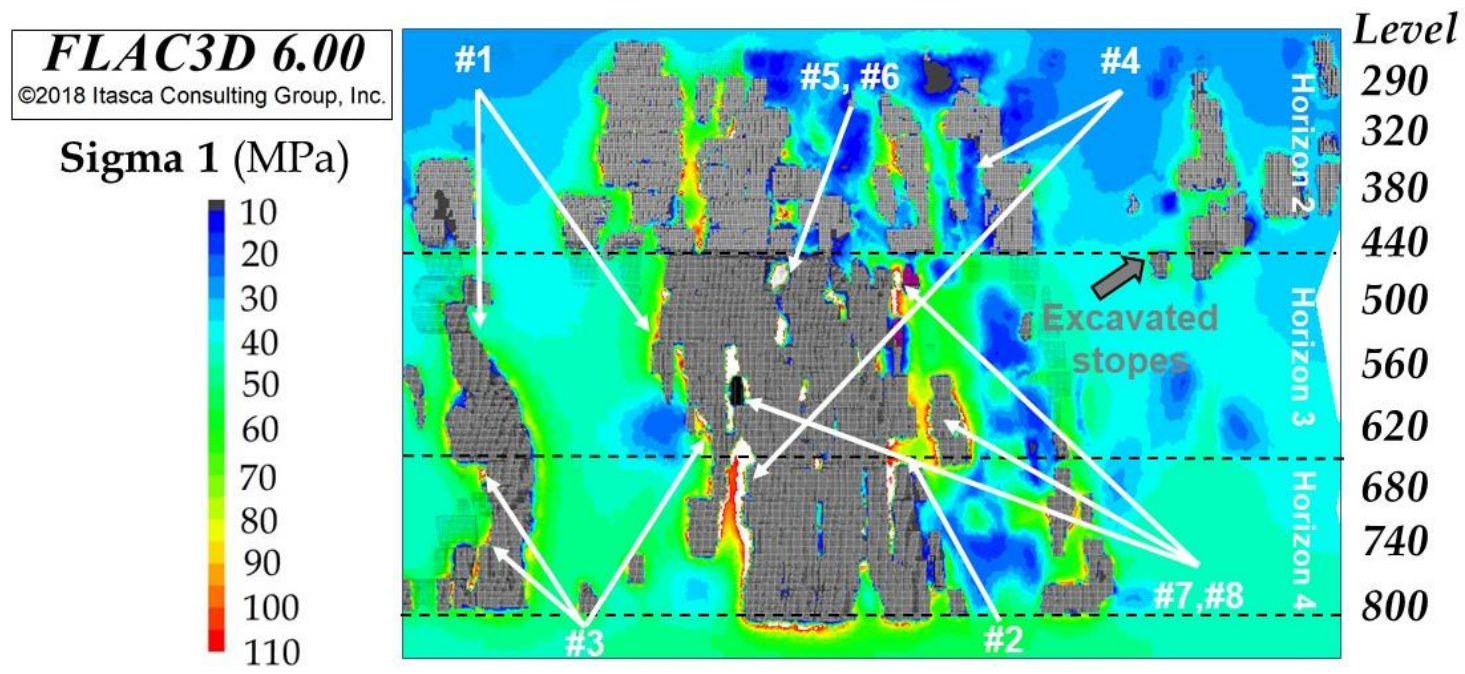

Figure 8. Contour of $\sigma_{1}$ on lens 5050 (longitudinal view) - Horizons 2, 3, 4 May 2020

Table V. Summary of stress increase factors

\begin{tabular}{|c|c|c|c|}
\hline Stress increase factor & Legend \# & $\begin{array}{l}\text { Impacted by } \\
\text { sequencing? }\end{array}$ & Remediation \\
\hline Depth & - & No & None \\
\hline Mining the edge of a large mined area & 1 & No & None \\
\hline Mining the sill pillar of a horizon & 2 & No & None \\
\hline Stope orientation & & No & None \\
\hline $\begin{array}{l}\text { Non-pyramidal shape / irregular } \\
\text { mining front }\end{array}$ & 3 & Yes & Pyramidal shape / regular mining front \\
\hline $\begin{array}{l}\text { Mining in the abutment stress of an } \\
\text { adjacent lens }\end{array}$ & 4 & Yes & $\begin{array}{l}\text { Mine the most continuous lens first and benefit } \\
\text { from shadowing in adjacent lenses }\end{array}$ \\
\hline Mining a secondary & 5 & Yes & \\
\hline $\begin{array}{c}\text { Mining in the middle of a large mined } \\
\text { area }\end{array}$ & 6 & Yes & $\begin{array}{c}\text { Mine such that the mined area is as continuous } \\
\text { as possible (i.e., without "holes" due to waste } \\
\text { pillars or secondaries that are mined late in the } \\
\text { sequence) }\end{array}$ \\
\hline $\begin{array}{l}\text { Mining close and/or toward a waste } \\
\text { pillar }\end{array}$ & 7 & Yes & $\begin{array}{l}\text { Limit the exposure to highly stressed waste } \\
\text { lenses by mining away from them instead of } \\
\text { toward them }\end{array}$ \\
\hline $\begin{array}{c}\text { Creating a waste pillar when mining } \\
\text { the stope }\end{array}$ & 8 & Yes & $\begin{array}{c}\text { Mine or blast waste pillars susceptible to } \\
\text { attracting very high stress }\end{array}$ \\
\hline
\end{tabular}




\section{Problematic areas}

After the automatic stress evaluation and scoring of each stope was done, results were plotted on longitudinal views for each of the main lenses at Eleonore to identify critical areas in terms of geomechanical risk. Figure 9 gives an example of such a view for lens 5050, already presented in Figure 8. We can see that the very highly stressed stopes (i.e., score $>40$ ) are due to:

- mining close to waste pillars at an advanced stage of mining

- late mining of secondaries

- stopes mined in the abutment close to a waste pillar a combination of remnant mining at a late stage, abutment of $\mathrm{H} 3$ and $\mathrm{H} 4$, and mining close to a waste pillar for stopes at the top of horizon 4 .

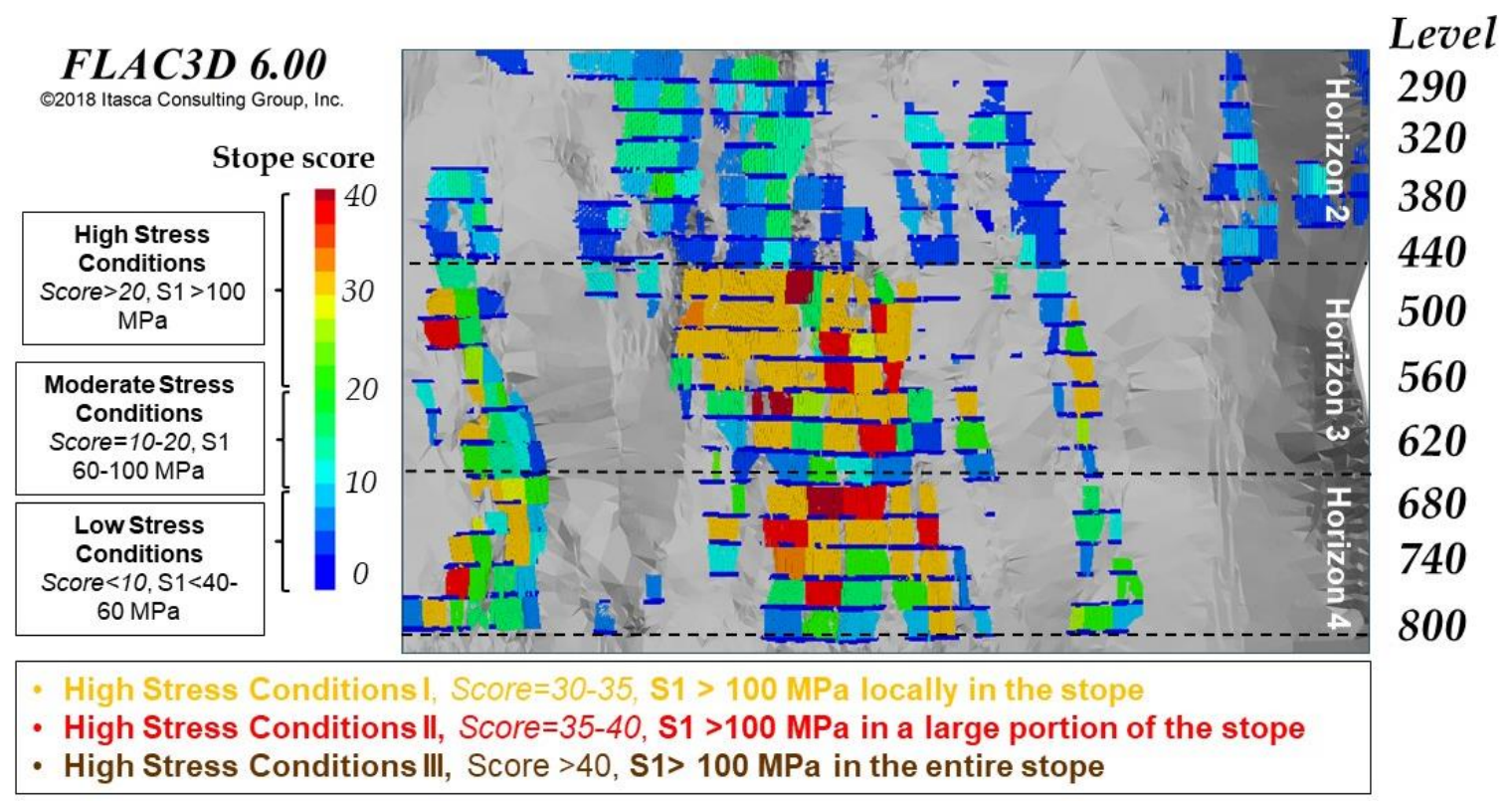

Figure 9. Lens 5050 - Longitudinal view. Stopes coloured by score value in horizons 3 and 4

\section{Sequence comparison}

Total stope score and expecting cleaning percentage

Figure 10 shows the histogram of total stope scores for the future mining of horizons 1 and 2 for Option 1 (i.e., no geotechnical restriction on the sequence) and Option 2 (i.e., flat back sequence). We can see that for both options, the majority of the stopes examined show manageable stress values in the stope and at the undercut. Only a few stopes per lens exhibit a high stress and associated high total score (i.e., are expected to be problematic); $7 \%$ (option 2) to $9 \%$ (option 1) are expected to feel high stress in $\mathrm{H} 1$, and $11 \%$ to $22 \%$ in $\mathrm{H} 2$. Based on the statistics gathered for past mining, the model predicts that for the base case sequence, $24 \%$ of the stopes will require more than $20 \%$ cleaning in $\mathrm{H} 1$ and $27 \%$ in $\mathrm{H} 2$, and $7 \%$ of the stopes will require more than $50 \%$ cleaning in $\mathrm{H} 1$ and $10 \%$ in $\mathrm{H} 2$. For the alternative sequence (option 2), the model predicts that $26 \%$ of the stopes will require more than $20 \%$ cleaning in $\mathrm{H} 1$ and $32 \%$ in $\mathrm{H} 2$, and $9 \%$ of the stopes will require more than $50 \%$ cleaning in $\mathrm{H} 1$ and $12 \%$ in $\mathrm{H} 2$. 

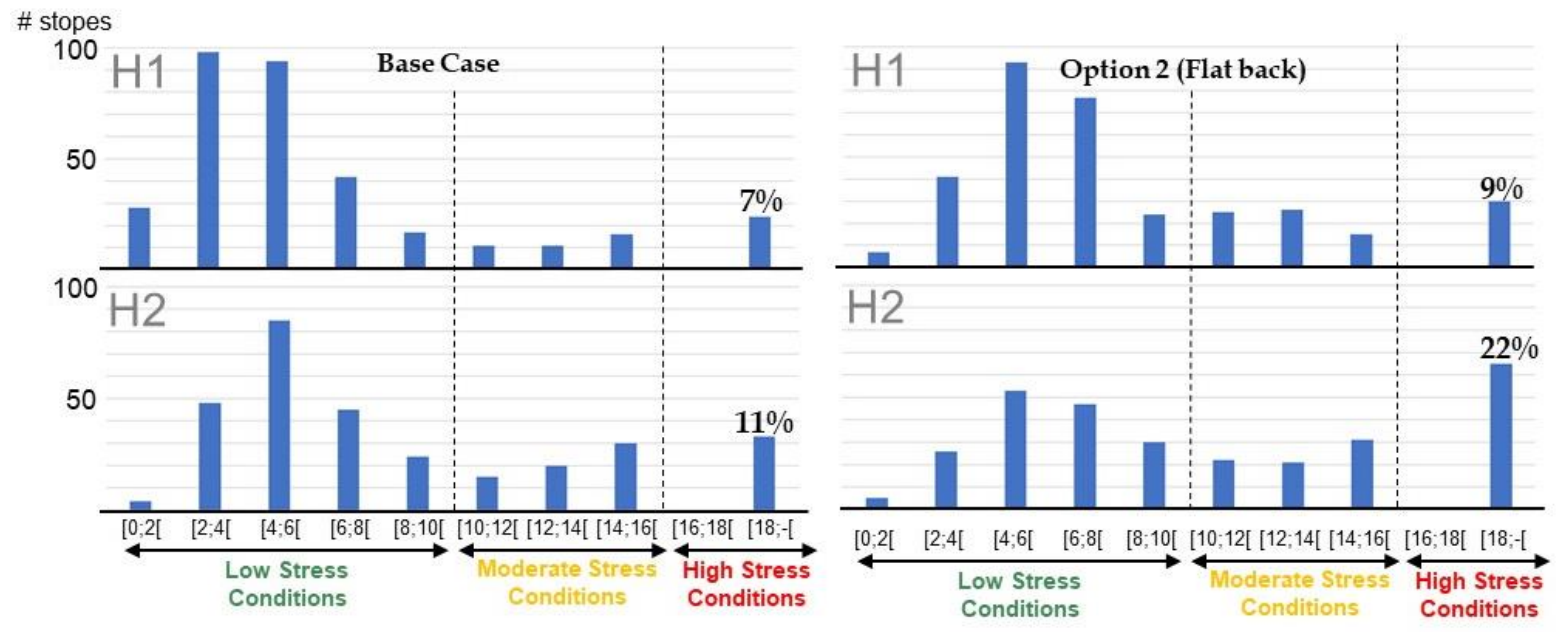

Figure 10. Histogram of total stope scores for future mining of horizons 1 and 2 for two sequence options

\section{Mean back stress}

Figure 11 shows the histograms of mean back stress for future mining of horizons 1 and 2 with the base case and alternative sequences. For both sequences, most drifts feel an average stress of 20 to $40 \mathrm{MPa}$, but a significant portion of the drifts feel an average stress of 40 to $60 \mathrm{MPa}$ (which corresponds to minor spalling) in horizons 1 and 2. Overall, the base case sequence results in slightly lower mean stress in the back of the on-ore drifts than option 2 for all horizons. The model also showed that locally, with both sequences, on-ore drifts can experience above $90 \mathrm{MPa}$ (hence expecting deep spalling) in the back for horizons 1 and 2: $8 \%$ versus $10 \%$ of the drifts for horizon 1 for the base case and alternative sequence, respectively, which doubles for horizon 2 (15\% versus $22 \%)$.
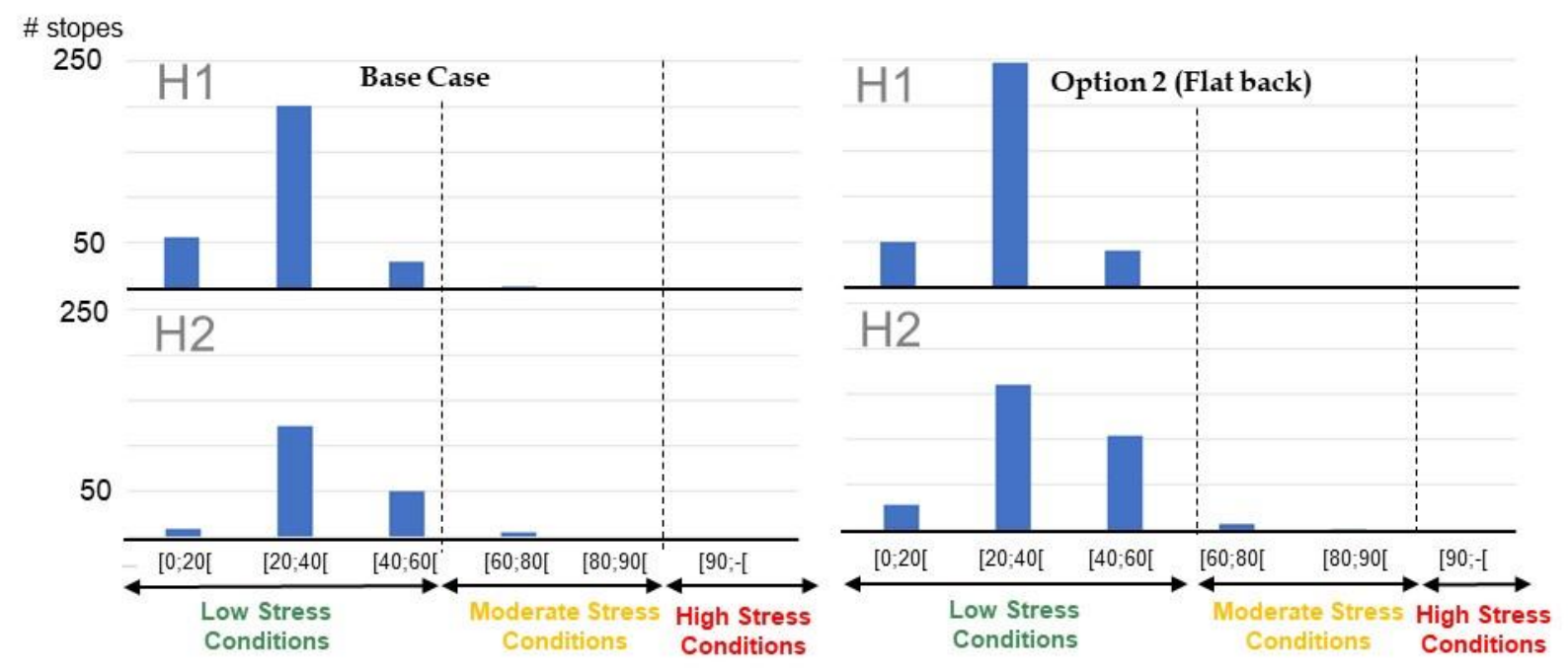

Figure 11. Histogram of mean back stress for future mining of horizons 1 and 2 for two sequence options

\section{Seismic moment}

Figure 12 shows the incremental seismic moment calculated in the model based on slip on horizontal joints in horizons 1 and 2 for past and future mining for the base case sequence and Option 2 (flat back). We can observe that a large peak in energy released is expected at the end of mining for the base case (after 2021), while a higher but steady energy release rate for Option 2 is associated with a lower rate at 
the end of mining (after 2021). Option 2 appears to allow for more rapid and steady release of energy (through horizontal joint slip) than the base case sequence, in which energy release is delayed towards the end of mining. The model also showed that in horizons 3 and 4 , we expect a significant increase in the energy release rate in the next three years (until the beginning of 2021), but this higher rate is expected to be similar to past rates in $\mathrm{H} 1$ and H2. Indeed, as we get deeper, the stress becomes less anisotropic and joints are more clamped; hence, conditions are less favourable to joint slipping. It is difficult to know exactly how the rate of energy release will impact seismic risk. Usually, it is preferable to have a steady rate so that energy does not get stored and released abruptly, especially when the energy is stored in the rock mass. At Eleonore, we suspect a lot of the energy is stored in the subhorizontal joints, and it is unclear what the consequence would be of a sudden slip and energy release on a large area of one of these joints. Since the seismic risk is always associated with significant uncertainties, the key components to manage it are: (1) a good seismic monitoring system that allows for careful tracking of the seismic trend as mining advances; and (2) a good ground support design that appropriately handles significant shearing on sub-horizontal joints (such as D-bolts).

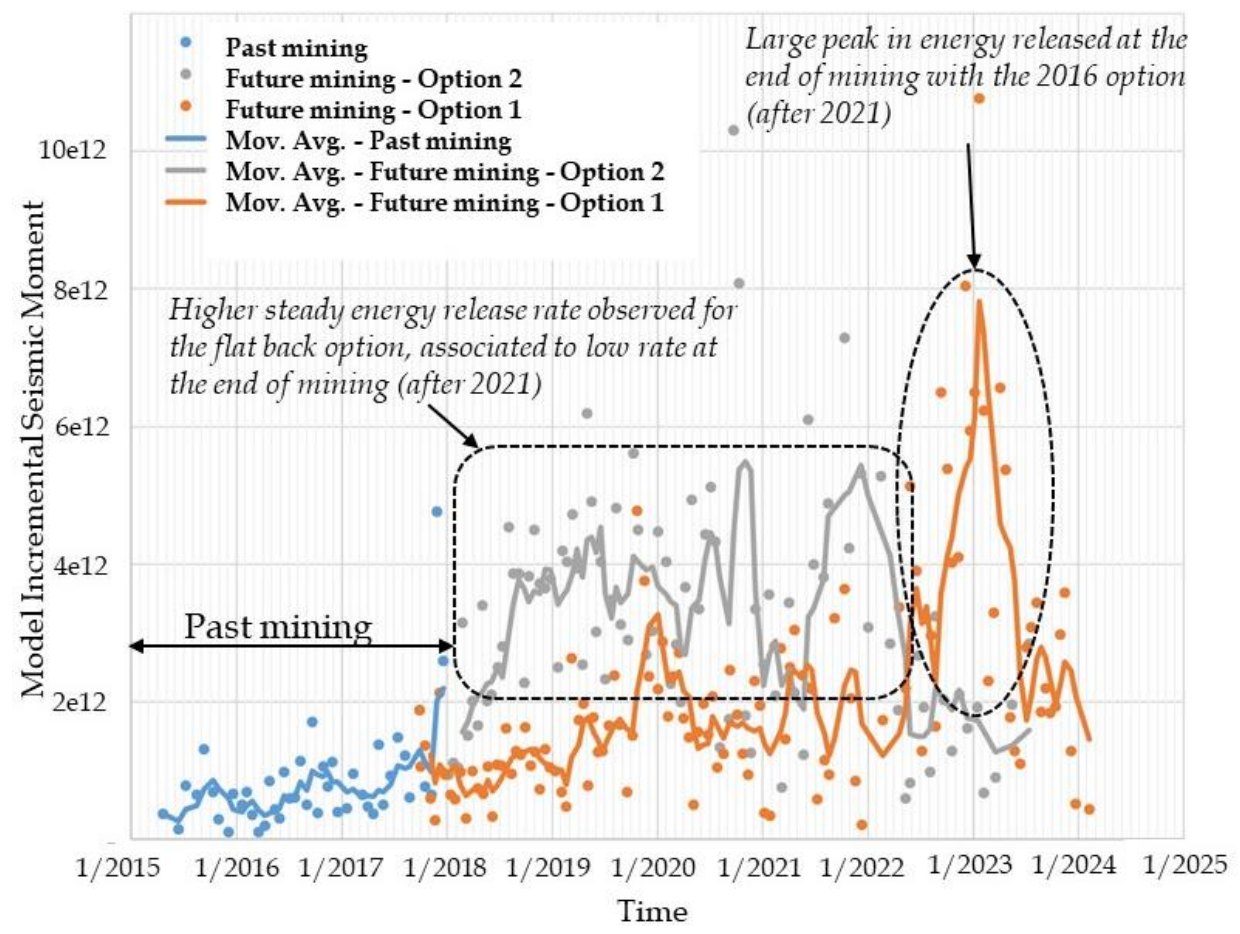

Figure 12. Incremental seismic moment calculated in the model based on slip on horizontal joints in horizons 1 and 2 for past mining and two sequence options for future mining

\section{Mining Sequence and Its Impact on geomechanical risk}

The following conclusions arise from the horizon-scale modelling exercise:

1. Option 2 (flat back sequence) results in similar geomechanical conditions to the base case (i.e., similar risks for drill hole and access stability) for horizons 1 and 2.

2. Both options should result in favourable mining conditions for the majority of stopes in both $\mathrm{H} 1$ and $\mathrm{H} 2$, for which only $10 \%$ of the stopes appear likely to be problematic (i.e., high stress level nearby or in the stope just prior to mining). In deeper horizons, 3 and 4 , conditions are more challenging, as around $40 \%$ of the stopes appear to be problematic.

3. The global approach to the sequence (e.g., flat back) does not have a strong impact on geomechanical performance due to very limited depth of failure in the plane of the orebody and the discontinuity of the lenses.

4. However, the sequence needs to be carefully adjusted locally, where multiple factors that increase stress combine, to limit the level of stress in the vicinity of the excavations and the 
associated geomechanical risk. Indeed, the model showed that as most on-ore accesses feel an average stress between $20 \mathrm{MPa}$ and $80 \mathrm{MPa}$ whichever sequence is used, local geometrical configuration and sequencing can cause the stress to locally increase above $130 \mathrm{MPa}$. Most highly stressed stopes are due to local configuration and arise from mining late secondaries or near highly stressed waste pillars and/or from lens interaction (i.e., mining in the abutment stress zone of an adjacent lens). Minor local adjustments to the sequence and widening (or mining) of waste pillars could mitigate some of these problems, while others may demand careful mining and locally heavy support.

\section{CONCLUSION}

The horizon-scale modelling exercise has highlighted several geomechanical risks associated with mining at Eleonore. Due to a combination of various factors, the stress felt by a stope just before mining can be very elevated compared to the in-situ stress, which induces different risks, such as instability of the undercut and surrounding accesses before mining (especially when large spans, such as intersections, are present and weaker ground conditions), difficulties to drill and instability of the overcut (i.e., stope back) after mining. Waste pillars and remnant stopes are one factor, as they attract significant stresses independent of the sequence chosen and usually do not yield due to the narrowmined width and high W:H ratio. Also, it appears likely that slip on horizontal joints at the top of mined stopes is a major contributor to mine seismicity for horizons 1 to 4 , playing a strong role in excavation stability. Ground support should be designed to sustain high shearing in the roof due to the excavation itself, as well as stress increases due to stoping.

The scoring and sequence comparison presented in this paper are solely based on the level of stress recorded in the stope and considering uniform Greywacke properties throughout the mine. Actual problems on site, such as a high percentage of blast hole cleaning, arise from stress conditions as well as local ground conditions, the quality of drilling, and time. The predictive capability of the model for ground instability issues is currently limited but could be significantly improved by considering local rock strength variations and structures that are believed to play a key role. Overall, as the mine is still at the early stage of mining and more challenging conditions are expected in the future, there is an opportunity to enhance data acquisition that would not only improve overall understanding and planning, but also further modelling, such as: (1) improved micro-seismic array coverage, especially in deeper horizons; (2) damage mapping of all the accesses to refine the understanding of access performance; and (3) standardised descriptions of blast hole cleaning and redrilling to be able to clearly differentiate between ground problems and operational problems.

\section{ACKNOWLEDGEMENTS}

The authors acknowledge the Eleonore ground control team for providing insights into the mine's ground behaviour in addition to qualitative input data, and the Eleonore management team for permission to publish this paper, with special thanks to Sophie Bergeron (Mine General Manager), Luc St-Arnaud and Adrienne Rispoli (Strategic Group). The authors also acknowledge the external review committee that helped guide this work and brought useful ideas and comments (Veronique Falmagne from Agnico Eagle, Brad Simser from Glencore and Patrick Andrieux from A2GC) as well as the contributions of other Itasca engineers to this work: Tryana Garza-Cruz, Miguel Fuenzalida and Ehsan Ghazvinian.

\section{REFERENCES}


Clark, I. H. 2006. Simulation of Rockmass Strength Using Ubiquitous Joints. Proceedings of the 4th International Symposium on Numerical Modelling in Geomechanics. Hart R. and Varona P. (eds). Itasca Consulting Group, Inc. Paper No. 08-07.

Corthésy, R. and M.H. Leite. 2017. Mesures Des Contraintes In-Situ Mine Éléonore, rapport préliminaire. Polytechnique Montréal, Bureau de la recherche et centre de développement technologique.

Guido, S. 2018. Seismic cluster best-fit planes VS UG mapping. Internal email-communication from GoldCorp to Itasca, January 2018.

Hoek E., Brown E. T. 1980. Underground Excavations in Rock. The Institution of Mining and Metallurgy, London, 93-101.

Hoek, E., C. Carranza-Torres and B. Corkum. 2002. "Hoek-Brown Failure Criterion - 2002 Edition," in NARMS-TAC 2002: Mining and Tunnelling Innovation and Opportunity, Vol. 1, pp. 267-273. R. Hammah et al, Eds. Toronto: University of Toronto Press.

Itasca Consulting Group, Inc. 2017. FLAC3D - Fast Lagrangian Analysis of Continua in 3 Dimensions, Version 6.0. Minneapolis: Itasca.

Oke, J., Kalenchuk K. 2017. MDEng Factual Report \#1015-F1704-01: Geotechnical Mapping and Site Characterization. Prepared for Goldcorp Inc., Eleonore Mine by MDeng.

Pierce, M. 2013. Numerical Modelling of Rock Mass Weakening, Bulking and Softening Associated with Cave Mining. ARMA e-newsletter. ARMA publications committee, spring 2013.

Yong, S. 2014. "In Situ Stress, Determination, Éléonore Project, Quebec," MIRARCO, Geomechanics Research Centre.

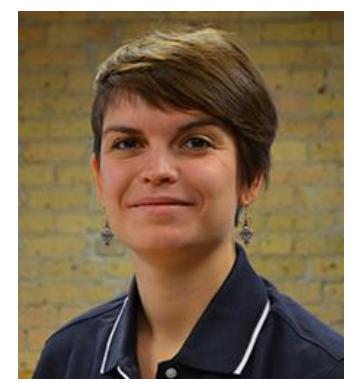

\section{Lauriane Bouzeran}

Geotechnical Engineer

Itasca Consulting Group

Ms Bouzeran is an engineer in the geotechnical and mechanical engineering fields. She has experience in the application of continuum and discrete numerical models to assess the stability of underground excavations and surface structures under static and seismic loading in the framework of civil and mining engineering. She has also participated in the development and application of an advanced bolt model (hybrid bolt) in Itasca's three-dimensional distinct element code 3DEC for simulation of ground support performance in highly fractured and bulked rock masses. Her modelling experience encompasses the use of several Itasca programs, including PFC3D, FLAC, 3DEC, FLAC3D, and Griddle. 
